\title{
Analysis of the transport - precariousness relationship in the peripheral areas of Casablanca
}

\author{
Ishak Hbiak $^{1,2, a}$, Abdelaziz Adidi ${ }^{1}$, El Hassan El Brirch ${ }^{2}$ and Jean-Pierre Nicolas ${ }^{3}$ \\ ${ }^{1}$ Institut National d'Aménagement et d'Urbanisme (INAU), Madinat Al Irfane, Rabat, Maroc \\ ${ }^{2}$ Ecole Hassania des Travaux Publics (EHTP), Km 7 Route d'El Jadida, Casablanca, Maroc \\ ${ }^{3}$ Ecole Nationale des Travaux Publics de l'Etat (ENTPE), Rue Maurice Audin, Vaulx-en-Velin, France
}

\begin{abstract}
Casablanca is the largest metropolis in Morocco and the Maghreb and one of the largest cities in Africa. However, like most cities in developing countries, it faces major problems in terms of planning and transport. The problems in transport are of different types and affect all areas of the city, especially the peripheral areas of Casablanca, which are experiencing significant difficulties in terms of accessibility, knowing that these areas are the most precarious. The aim of this work is to confront on the one hand the global GIS analysis of the transport supply and its relation with the precariousness of the populations, and on the other hand the real problem of access to economic opportunities because of the exorbitant costs of public transport in relation to the income of these peripheral populations, taking into account the case of the peripheral city of Errahma. This second analysis was carried out through a field survey, on the area of the new city of Errahma. Initial analysis of this work has confirmed the existence of a very strong relationship between transport supply, loss of economic opportunity and precariousness in these peripheral areas.
\end{abstract}

\section{Introduction}

Transport development has always been linked to economic development. It's in the same time factor and result of economic activity.

Indeed, firstly transport is considered as a factor of production of goods and services. Transportation participates in the added value to goods and services. On the other hand, the development of transport is an implication of the changing economy.

Like most large cities in developing countries, Casablanca has many transportation problems: both in terms of quantity and quality. These problems can dampen the economic activity of the population, especially the most fragile one $[1,2,3]$.

The question of the equity of access to the city and urban services has been the subject of a lot of researches in the field of urban studies, but the consideration of social inequalities and the use of the notion of accessibility in the field of transport can still today be considered undeveloped. Mobility can be seen as a condition of social integration. [4]

Besides, "The fit between transport alignments and contemporary poverty mappings is rarely considered in the design of transport systems funded or leveraged through the public purse" [5]. In this context, known by low supply of urban public transport services, there is the question of the confrontation of this offer with the socioeconomic characteristics of the population of the various districts of Casablanca, especially the question of the confrontation of the characteristics of the urban transport supply and the poverty data in Casablanca, to test the hypothesis where poorest neighborhoods are the least served by public transport. This hypothesis has been the subject of several studies carried out on cities in developing countries $[6,7,3]$.

Another research has shown the causal link between public transport supply and urban distribution of poverty: "access to public transportation plays a significant role in determining the spatial distribution of poverty in a metropolitan area, and if expansion of bus public transit is a factor contributing to the suburbanization of poverty" [8]. In Casablanca, this link is not proved because of the weakness of the urban transport offer.

Transport and poverty has also been dealt with in a broader context evoking the notion of "transport poverty" or "energy poverty". [9, 10, 11].

\footnotetext{
${ }^{\mathrm{a}}$ Corresponding author: ishak.hbiak@gmail.com
} 


\section{Study area and used data}

\subsection{Study area}

Casablanca is the first metropolis of Morocco and North Africa, and one of the largest cities in Africa. The area of Casablanca agglomeration spreads over $1615 \mathrm{~km}^{2}$.

According to the High Commission for Planning (HCP), Grand Casablanca has more than 4.3 million inhabitants, and Casablanca city alone totals 3.4 million inhabitants, with a large part of young population $(31 \%$ are under 15). Casablanca is also a very active city with an activity rate of $51 \%$. It hosts $39 \%$ of the production units in Morocco and $60 \%$ of the industrial workforce [12].

The Grand Casablanca region still has about 500 shanty towns in which nearly 111,500 families are crowded (according to statistics of 2012), despite all the efforts of the government in the program "Cities without slums" [13].

This demographic pressure has led to a still very strong urban sprawl in action, and strong demand on the various urban services.

\subsection{Used data}

In our work, we used first, the data of the supply of urban public transport in Casablanca. These data are composed of the mapping of the bus network, as well as the route of the first tramway in operation since late 2012 [14-15].

In addition to these offer transportation data, we used data on poverty in the region of Casablanca in 2014. These data were produced by an investigation of the territorial authorities of Casablanca in collaboration with the High Planning Commission and other actors, such as the social development Agency (ADS) [4-16].

Figure 1 presents the results obtained from this survey for the different districts of Casablanca and the province of Nouacer.

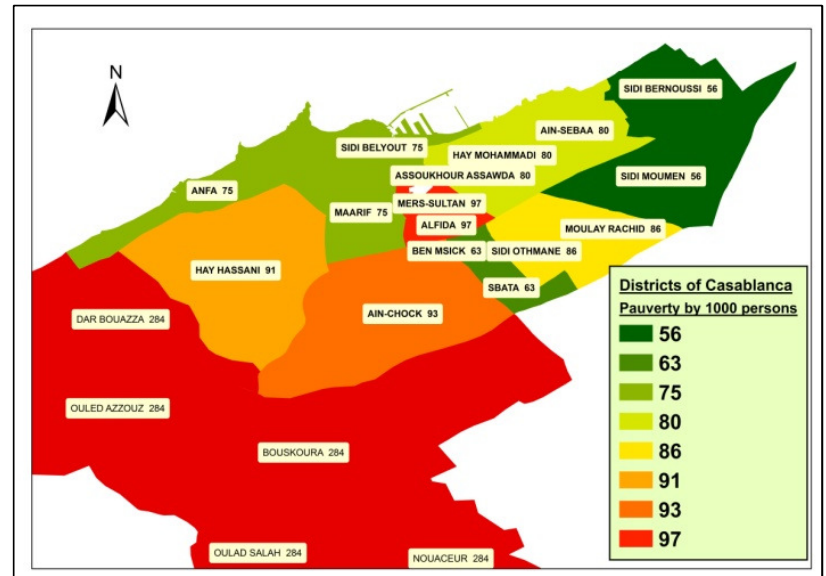

Fig. 1. Casablanca Poverty Map

We have also exploited spatial data related to the territory of Casablanca, including the administrative division, as well as a source of very high resolution satellite imagery (up to a resolution of 30 centimeters).

We also used a layer showing the main economic activity zones in the Casablanca region territory in order to analyze the relationship between economic opportunities and transport.

We have also conducted a survey of households in certain peripheral areas of the city of Casablanca. Here after, we will present some preliminary results of this survey concerning the peripheral city of Errahma.

\section{Results and analysis}

\subsection{Development of a spatial database}

Before starting our analytical work we have proceeded with the compilation of all collected data in a unified spatial database and in a GIS environment.

Figure 2 illustrates Casablanca's public transport supply network, consisting of bus lines and the first tram line, based on the developed database.

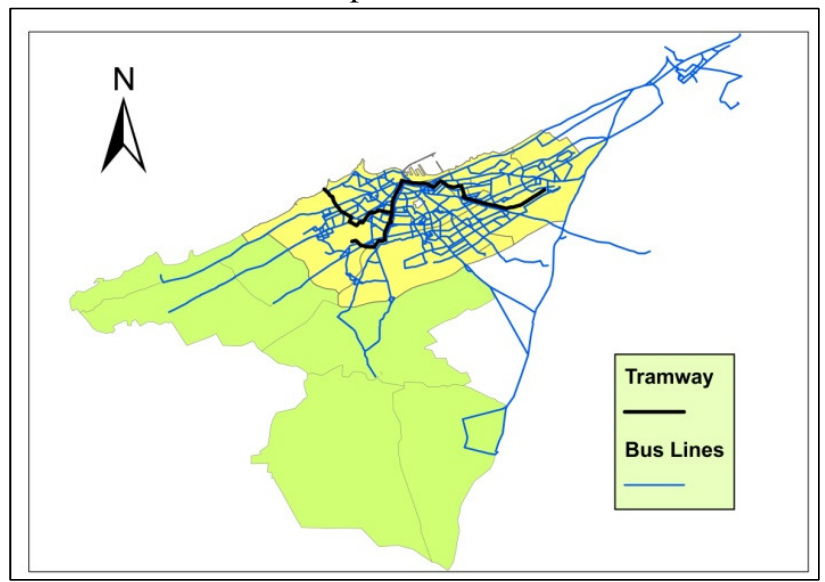

Fig. 2. The Casablanca public transport supply network

The spatial database has helped us perform spatial analysis relative to our original problem using a GIS tool.

\subsection{Density of public transport supply in Casablanca}

After mapping the network of public urban transport in Casablanca, we conducted an analysis of its density in space. So we defined an indicator to highlight the concentration of supply in certain districts of Casablanca. The map in figure 3 shows the results.

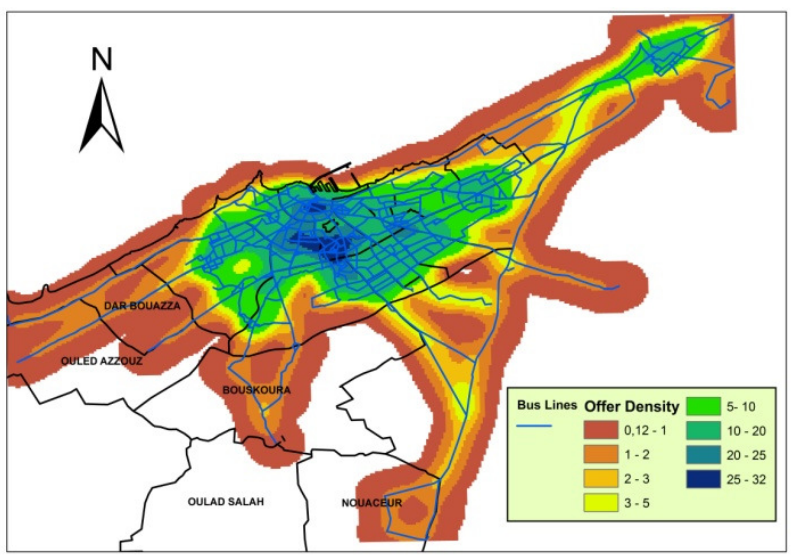

Fig. 3. The density of the supply of urban public transport 
The analysis of this map shows the concentration of supply in the central districts of the city, with a gradual decrease towards the periphery. Some peripheral areas experiences almost total absence of the network.

\subsection{Urban planning and transportation in Casablanca}

We looked after to the relationship between the distribution network and urban form in Casablanca.

The analysis of the directional distribution of the urban public transport network in Grand Casablanca confirms the historical link between supply of transportation and urban form concentrated around the port. Figure 4 illustrates directional distribution of the urban public transport.

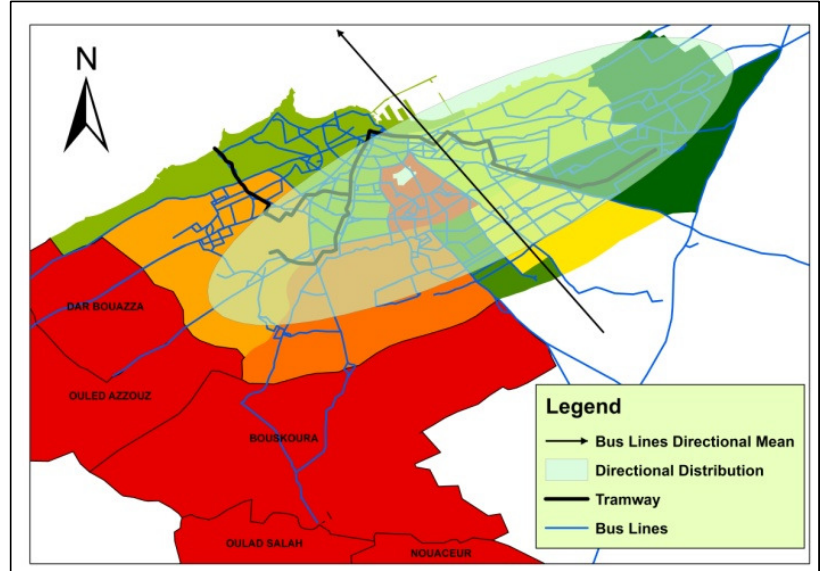

Fig. 4. Directional distribution of the urban public transport

\subsection{Precariousness and accessibility to the urban transport network in Casablanca}

In this step of our analysis, we have calculated another indicator to compare access to the network of urban public transport and the precariousness of the populations served by this offer.

The result is shown in the figure 5, and it clearly shows that the poorest populations, in the majority of cases, are also the least served by public transport offer.

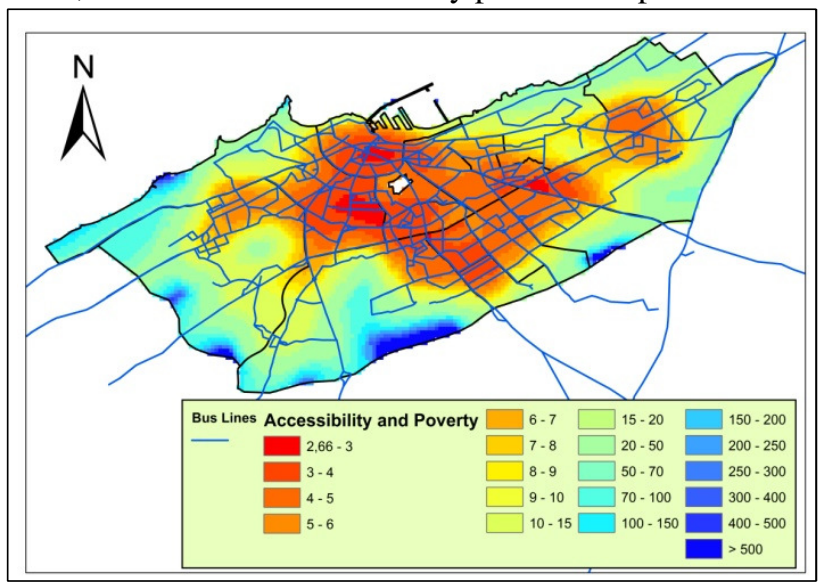

Fig. 5. Poverty and accessibility to transportation

\section{5 transport and economic opportunity of the peripheral populations of Casablanca}

Finally, we were interested in verifying the hypothesis of the negative effect of transport supply on the economic opportunity of the peripheral populations of Casablanca. We took the example of the peripheral city of Errahma.

Figure 6 presents the main areas of economic activity in the Casablanca region. It shows that the most important economic zones of the Casablanca region are concentrated in the North and it is the opposite of the city of Errahma which is south of the city of Casablanca.

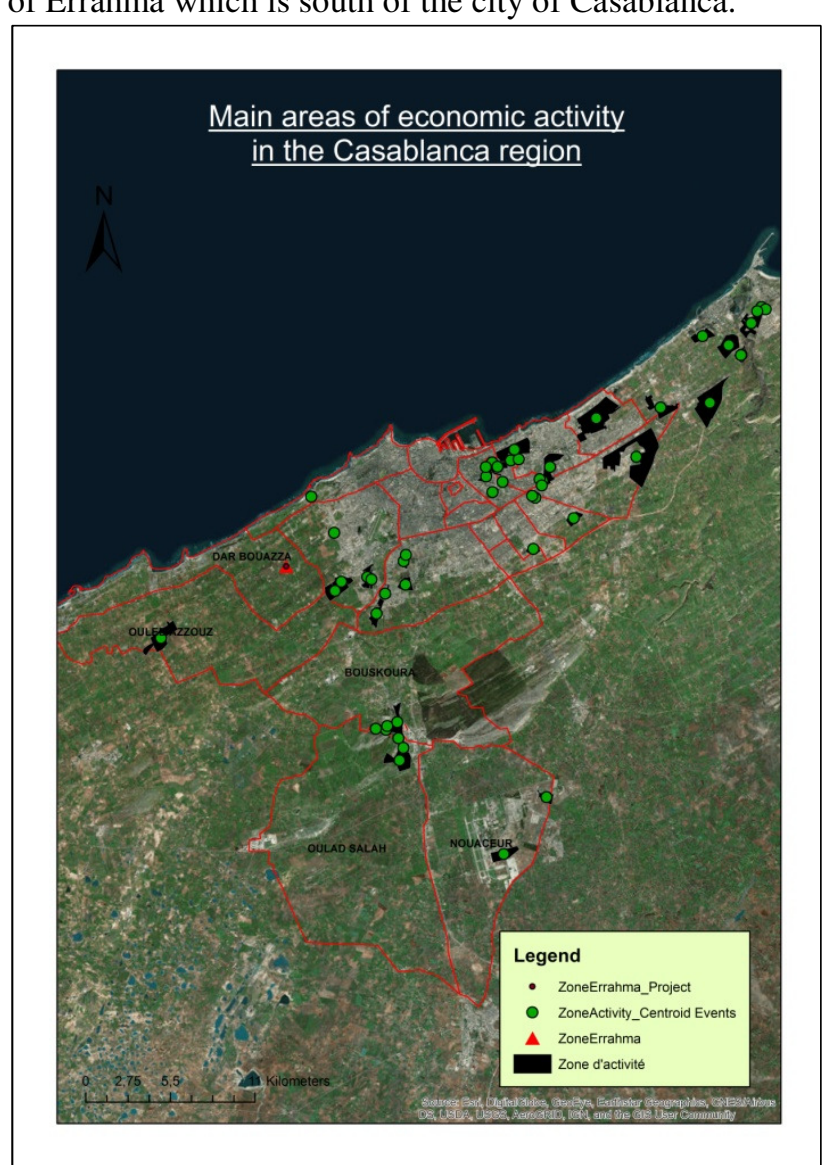

Fig. 6. Main areas of economic activity in the Casablanca region

We have analyzed the distance between Errahma and the economic activity zones of Casablanca. Figure 7 shows the proximity of these zones along concentric rays between 5 and 40 kilometers.

It can be seen that the main economic activity zones of Casablanca are at distances between $10 \mathrm{~km}$ and $20 \mathrm{~km}$ from Errahma, and even up to $40 \mathrm{~km}$ for certain areas. This is equivalent, in terms of time, to trips lasting between $1 \mathrm{~h}$ and $2 \mathrm{~h} 20 \mathrm{~min}$.

To confirm this result, we conducted a survey of households in the city of Errahma. The purpose of this survey was to answer essentially to the questions relating to the mobility of people living in Errahma. The results of this survey relate to a sample of 60 households.

Preliminary results show that the average of the ratio of the monetary cost of travel compared to the income of the outlying households of Errahma is much higher than the national average. 


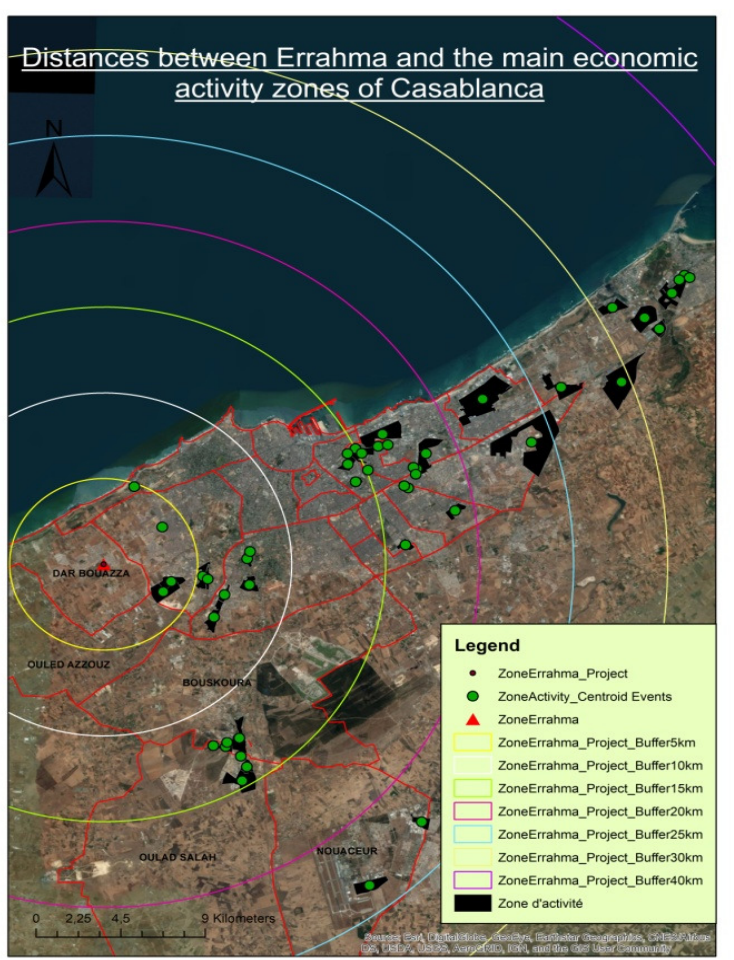

Fig. 7. Distance between Errahma and the main economic activity zones of Casablanca

We note also that Errahma's household travel time is very high and can in some cases reach 4 to 5 hours a day.

We notice that more than a quarter of households say they have lost an economic opportunity mainly because of the high generalized cost (Time, Cost, Security ...) of the trips to and from the city of Errahma.

\section{Conclusion}

Our study shows that the new urban sprawl has concentrated precarious population on the peripheral areas of the city of Casablanca without supporting this extension by an offer of adequate transport and thus decreased its potential access to economic opportunities.

This conclusion raises questions about the equity in the supply of urban public transport in Casablanca and the choice of the proposed urbanization model for the Casablanca region and Morocco as a whole.

The results of the survey showed that the transport supply of a peripheral district (case of Errahma) can be a serious obstacle to access to economic opportunities. A low supply of transport therefore in this sense appears as a cause of impoverishment of households in peripheral areas.

\section{References}

1. Godard, X. (2000). Urban mobility in developing cities: Difficulties of measures, uncertainty of trends and of sustainability appraisal. In Urban transportation and environment. Proceedings of the international conference CODATU IX, Held Mexico City, 11-14 April 2000.
2. Diaz Olvera, L., Plat, D., \& Pochet, P. (2005). La ville hors de portée? Marche à pied, accès aux services et ségrégation spatiale en Afrique subsaharienne. Espace populations sociétés. Space populations societies, (2005/1), 145-161.

3. Rebouha, F., \& Pochet, P. (2009). Mobilité et accès à la ville pour le travail des populations pauvres du périurbain d'Oran. Cahiers de la Méditerranée, (78), 335-353.

4. Sylvie, F., \& Gallez, C. (2013, January). Mobilité, accessibilité et équité: pour un renouvellement de l'analyse des inégalités sociales d'accès à la ville. In Colloque International Futurs urbains: Enjeux interdisciplinaires émergents pour comprendre, projeter et fabriquer la ville de demain.

5. Grieco, M. (2015). Poverty mapping and sustainable transport: A neglected dimension. Research in Transportation Economics, 51, 3-9.

6. Olvera, L. D., Plat, D., \& Pochet, P. (2005). Marche à pied, pauvreté et ségrégation dans les villes d'Afrique de l'Ouest. Le cas de Dakar.

7. Olvera, L. D., Plat, D., Pochet, P., \& Audin, R. M. (2011). Pauvreté, mobilité quotidienne et accès aux ressources dans les villes subsahariennes. Dynamiques de Pauvretés Et Vulnérabilités en Démographie Et en Sciences Sociales: Actes de la Chaire Quetelet 2007, 281.

8. Pathak, R., Wyczalkowski, C. K., \& Huang, X. (2017). Public transit access and the changing spatial distribution of poverty. Regional Science and Urban Economics, 66, 198-212.

9. Lucas, K., Mattioli, G., Verlinghieri, E., \& Guzman, A. (2016). Transport poverty and its adverse social consequences. In Proceedings of the institution of civil engineers-transport (Vol. 169, No. 6, pp. 353365). Thomas Telford (ICE Publishing).

10. Berry, A., Jouffe, Y., Coulombel, N., \& Guivarch, C. (2016). Investigating fuel poverty in the transport sector: toward a composite indicator of vulnerability. Energy Research \& Social Science, 18, 7-20.

11. Mattioli, G., Lucas, K., \& Marsden, G. (2018). Reprint of Transport poverty and fuel poverty in the UK: From analogy to comparison. Transport Policy, 65, 114-125.

12. au Plan, H. C., Direction de la Statistique (2016). Le Maroc des régions 2014.

13. Ministry of Housing and Urban Policy, Morocco (2012). "Cities without slums" program.

14. Hbiak, I., Adidi, A., Nicolas, J.P., El brirchi, E. (2016). Choix d'indicateurs de mobilité urbaine durable pour le territoire de Casablanca. In Proceedings of the 1st AMSR Congress and 23rd APDR Congres (pp 76-85).

15. Hbiak, I., Adidi, A., Nicolas, J.P., El brirchi, E. (2016). Analyse de la desserte des transports publics urbains sur le territoire de Casablanca par les systèmes d'information géographique. In $3^{\text {ème }}$ Colloque International sur le Monitoring des Systèmes Industriels, CIMSI'2016, Fès-Maroc.

16. Wilaya de Casablanca (2015). Carte de pauvreté de la région de Casablanca. 